\title{
Fuel Characterization and Simulation Study of Dewatered Domestic Wastewater Sludge Gasification Using ASPEN Plus
}

\author{
${ }^{* 1}$ A. B. A. Ibrahim and ${ }^{2} \mathrm{H}$. Akilli \\ *1Faculty of Engineering, Department of Mechanical Engineering, University of Blue Nile, Sudan \\ ${ }^{2}$ Faculty of Engineering, Department of Mechanical Engineering, Cukurova University, Turkey
}

\begin{abstract}
Dewatered domestic wastewater sludge (DDWS) is one of the largest contributors of waste material in the world, and it immediately elevates local environmental problems, especially in the urban area. The conversion of this material into a usable form of green energy, such as syngas through gasification, can be a vital solution. Hence, this method not only solves the environmental issues related to DDWS disposal but also participates as an energy source. To achieve this goal, the essential fuel characterization, which includes initial moisture content, high heating value, ultimate analysis, and proximate analysis, were carried out to assess the potential energy in DDWS. Due to the high expenses of the successful design of the gasifier reactor, and there are no efficient methods to predict the gasification performance, the model of the DDWS gasification process using ASPEN Plus software was developed. As ASPEN Plus software does not contain a built-in gasifier reactor model, a combination of various reactors is used to simulate the gasification processes. These processes were divided out into two stages. In the first stage, DDWS was decomposed into its element by specifying yield distribution. By using Gibbs free energy minimization approach, the gasification reactions were modeled. The current model was validated with the previously published work. From the characterization findings, DDWS showed high initial moisture content $84.64 \%$ and potential energy with $16.84 \mathrm{MJ} / \mathrm{kg}$ high heating value. The proximate analysis based on the dry base of DDWS exhibited that more than $55.42 \%$ of their mass is composed of volatile materials, and ash content is found to be less than $25.79 \%$. The elemental of carbon, hydrogen, nitrogen, sulfur, and oxygen component in the DDWS sample was $34.29 \%, 5.20 \%, 5.80 \%, 3.12 \%$, and $25.80 \%$, respectively. By applying operating parameters, which include reaction temperature, reaction pressure, airflow rate, and moisture content, it's found that the increase in reaction temperature (673-1673K) enhanced the production of $\mathrm{CO}$ and $\mathrm{H}_{2}$ while increasing reaction pressure adversely affected the generation of $\mathrm{H}_{2}$ and $\mathrm{CO}$. The increase in the airflow rate increases $\mathrm{CO}_{2}$ mole fraction in syngas and shift the gasification process to combustion. The heating value of syngas sharply decreased with the increase in the DDWS moisture content. From the simulation results, ASPEN Plus simulator software is presented with the high capability to be used as a predictive tool for optimization of the gasifier performance.
\end{abstract}

Key words: Dewatered domestic wastewater sludge, fuel characterization, gasification, Operating parameter, ASPEN Plus

\section{Introduction}

Dewatered domestic wastewater sludge (DDWS) can be defined as a soft mud or mire, a slimy precipitate produced from the sewage [1]. In the wastewater treatment, sludge by far is the largest in product volume, and its disposal process causes perhaps one of the most complex

*Corresponding author: Address: Faculty of Engineering, Department of Mechanical Engineering University of Blue Nile, 26611, Al-Damazin SUDAN. E-mail address: saadalla_85@yahoo.com, Phone: +905365448250 
environmental problems for an engineer working in this field to manage $[1,2]$ because it contains unsuitable constituents such as organic, inorganic elements and pathogenic micro-organisms. Due to this, it is considered, universally, as unsightly material and may cause some harmful side effects which have to be dealt with the least public exposure. Furthermore, the management of DDWS waste slowly increases the financial burden of wastewater treatment companies, especially in high population areas such as urban and suburban areas. There are numerous environmental and health risks associated with the disposal of DDWS, if not mitigated, will cause serious problems for the country. In 2007, the yearly feed-rate of domestic wastewater entering wastewater treatment plants throughout the country was estimated at 4.9 million cubic meters [3], and the cost to treat and manage its disposal was at US\$ 0.3 billion [4]. One solution to solve the disposal issues related to DDWS is to convert this waste material into an alternative fuel. Therefore, this does not only help solve environmental issues related to DDWS disposal but also contribute as an energy source.

The conversion of DDWS into a usable form of energy can take place through biological, thermochemical, physical, and hydrothermal processes [5]. Among these conversion techniques, thermochemical gasification shows a promising approach to convert DDWS into clean syngas fuel. Syngas is mainly a mixture of combustible gases such as $\mathrm{H}_{2}, \mathrm{CO}$ and $\mathrm{CH}_{4}$, and noncombustible gases such as $\mathrm{CO}_{2}$ and $\mathrm{N}_{2}[5,6]$. The gasification is a complex process that includes drying, pyrolysis, combustion, and reduction processes, as elaborated by Diyoke et al. [7]. Typically, the quality of syngas is affected by some essential parameters such as biomass characterization, process operation parameters, and the gasifier reactor design [8]. The biomass characterizations depend on the biomass source. The significant biomass characterizations on gasification process include size, density, ultimate analysis (carbon $(\mathrm{C})$, hydrogen $(\mathrm{H})$, nitrogen $(\mathrm{N})$ and sulfur $(\mathrm{S})$ ) and proximate analysis (volatile matter (VM), fixed carbon (FC) and ash) [9, 10]. The operation parameters in biomass gasification are reaction temperature, reaction pressure, equivalence ratio, and moisture content.

Kirsanovs et al. [11] investigated the effect of wood chips moisture content on the syngas production efficiency. They found lower moisture content was favorable for syngas production. Moreover, the high moisture content decreases the heating value of syngas as reviewed by Susastriawan et al. [8]. McKendry [12] mentioned that the reduction in the syngas heating value at high moisture content is due to the incomplete pyrolysis process. The effect of reaction temperature through the gasification process was explored by Liu et al. [13]. They stated that high temperatures promoted tar cracking, then improved the endothermic gasification reaction rate and enhanced the yield of syngas production. Wang et al. [14] studied the effect of reaction temperature on the gasification of pinewood sawdust and cotton stalk. They observed that the percentage of $\mathrm{CO}$ and $\mathrm{H}_{2}$ in syngas increases with increasing reaction temperature thus increases the heating value of syngas. In contrast, the increase in the reaction pressure decreases the percentage of $\mathrm{CO}$ and $\mathrm{H}_{2}$ in syngas [15]. Kaupp and Gross [16] stated the gasification process shifts from the pyrolysis domain to the combustion domain with the increase in the air-fuel ratio [17]. In general, the results of the previous studies have a similar trend. However, the optimum operating parameters for biomass gasification are affected by biomass characterization and gasifier design. 
The design of gasifier reactor dimensions and capacity of the syngas production assign based on the specific biomass characterizations. Moreover, the characterizations of one type of biomass are different from others. From this, biomass is considered as the most vital key in the gasifier reactor design. Due to the high expenses of gasifier design, many biomass gasification models were carried out to study the feasibility of biomass gasification and to predict the amount and composition of syngas production [7, 18-20].

Before convert DDWS into syngas, the essential fuel characterizations were carried out to assess its potential energy. This characterization includes initial moisture content, high heating value (HHV), ultimate analysis, and proximate analysis. Moreover, since there are no available efficient methods to predict the quality of produced syngas due to less understanding of the thermodynamic process, the simulation of the DDWS gasification process using ASPEN Plus software was investigated. In this simulation study, the steady state model is employed to describe the DDWS gasification process. The operating parameters, which include reaction temperature, reaction pressure, airflow rate, and moisture content, were used to study their effect on the produced syngas composition.

\section{Materials and Method}

\subsection{Fuel Characterization}

DDWS samples used in this study were collected from domestic wastewater treatment which located in the southern region in Turkey. To assess the potential energy in DDWS, the samples in the received form were first dried by using a convection oven at $15 \pm 0.5^{\circ} \mathrm{C}$ according to ASAE S358.2 standard to obtain the initial moisture content. Through the drying process, the weight of samples was regularly checked to obtain the weight loss (water evaporation) with associated time. Thus, the final form of dried samples was labeled and stored in airtight plastic containers. Then, HHV of dried sample was measured to obtain the amount of energy based on the ASTM D2015 standard. The reported HHV results in this study were measured using the SDACM-3100 bomb calorimeter. In this study, the CHNS analyzer was used to measure the elemental composition in DDWS sample in terms of carbon $(\mathrm{C})$, hydrogen $(\mathrm{H})$, nitrogen $(\mathrm{N})$, and sulfur $(\mathrm{S})$. The oxygen content was determined by the difference of the summation of $\mathrm{C}, \mathrm{H}, \mathrm{N}, \mathrm{S}$, and ash content from 100. Furthermore, the thermogravimetric analyzer (TGA) was used to determine the proximate analysis of DDWS samples concerning the ASTM E113108 standard. The proximate analysis presents the amount of volatile matter (VM), fixed carbon (FC) and ash contents in DDWS samples. Each sample with a known weight was placed in the sample crucible and subjected to heating up to $600^{\circ} \mathrm{C}$ in an inert gas environment and then in oxidant gas as the temperature rose to $850^{\circ} \mathrm{C}$. The trend generated by the TGA device for each sample was then examined for peaks to determine the amount of volatile matter, fixed carbon, and ash based on mass loss.

\subsection{Gasification simulation model development}

ASPEN Plus software is used to develop a kinetic free equilibrium for the gasification process. However, as the gasifier model does not exist in the ASPEN Plus process simulator, the 
gasification process in this study was modeled in two stages. In the first stage, the feedstock decomposed into volatile components and char in the second stage. The FORTRAN statement was employed in the calculator block to specify the yield distribution in this stage. Finally, the gasification reaction was modeled by minimizing Gibbs free energy.

The basic assumptions in the model are: (i) Steady state kinetic free model, (ii) Isothermal system, (iii) All sulfur goes to $\mathrm{H}_{2} \mathrm{~S}$, (v) Only $\mathrm{NH}_{3}$ forms, no oxides of nitrogen are produced, and (iv) Tars and other products are assumed as non-equilibrium products to reduce hydrodynamics complexity.

Among the equation of states that available in ASPEN Plus, Peng-Robinson equation with Boston-Mathais alpha function (PR-BA) used in the current study. This method improves the correlation of the pure component vapor pressure when the temperature is very high because the alpha parameter in this package is a temperature-dependent variable. Moreover, the enthalpy and density model for non-conventional components (biomass and ash) were specified as HCOALGEN and DCOALIGT respectively.

\subsubsection{Model Description}

DDWS is defined as a non-conventional component in ASPEN Plus and specified by using ultimate and proximate analysis, as shown in Table 1. In the model simulation, four block models used to simulate the gasification process. Moreover, the typical DDWS gasification processes and calculation procedures used in ASPEN Plus is presented in Fig.3. The RGibbs block model is used to simulate the gasification process of DDWS. RGibbs block models chemical equilibrium by minimizing Gibbs free energy and can handle three-phase chemical equilibrium. However, the equilibrium calculation cannot be done because DDWS is defined as a non-conventional component. Concerning this challenge, it is necessary to feed DDWS into the simulation based on it is elements composition $(\mathrm{C}, \mathrm{H}, \mathrm{N}, \mathrm{S}$, and $\mathrm{O})$. For this purpose, the RYield block model is employed. In this case, it is assumed that the volatile content obtained from the proximate analysis of DDWS is equal to the total yield of volatiles. Moreover, the FORTRAN statement is connected to the RYield block model to calculate the yield distribution of DDWS into its components. The reaction temperature related to DDWS decomposition is modeled in the RGibbs block model. This block calculates the syngas composition by minimizing Gibbs free energy and assumes complete chemical equilibrium. The air stream is attached to the RGibbs block model where the chemical equilibrium calculates. Finally, the ash is separated from the syngas by using the Sep block model based on the split fractions.

\subsubsection{Model Validation}

The developed model validated by using the experimental result of municipal waste material (MSW) gasification published by [20]. Table 3 showed that the simulation results are in good agreement with the experimental result for MSW. In this simulation, the results showed better agreement with the syngas composition of other authors, yet it still needs to be validated with experimental data in the future. 
Table 1. Description of ASPEN Plus unit operation models

\begin{tabular}{|l|l|l|}
\hline ASPEN Plus ID & Block ID & Description \\
\hline RYield & DECOMP & $\begin{array}{l}\text { Yield reactor-converts non-conventional biomass into conventional } \\
\text { components by using FORTRAN statement. }\end{array}$ \\
\hline RGibbs & GASIF & $\begin{array}{l}\text { Gibbas free energy reactor- handles three phase equilibrium and } \\
\text { calculates syngas composition by minimizing Gibbs free energy. }\end{array}$ \\
\hline Sep & SEPARAT & Separates gases from ash by specifying split fractions. \\
\hline
\end{tabular}

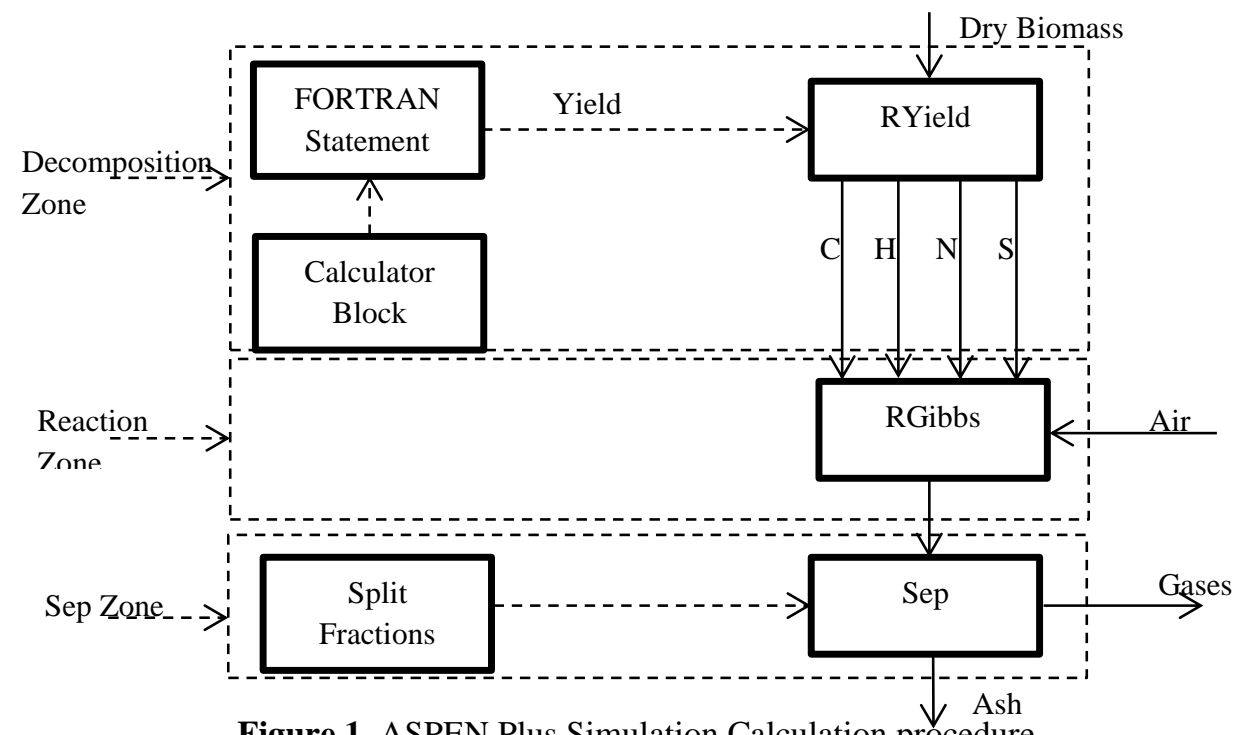

Figure 1. ASPEN Plus Simulation Calculation procedure

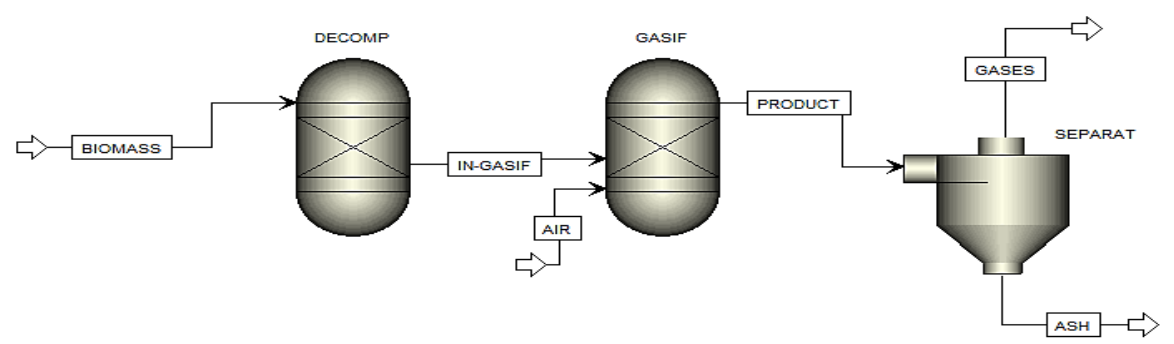

Figure 2. Typical ASPEN Plus Simulation procedure for dewatered domestic wastewater sludge gasification

Table 2. Experimental result vs model prediction of MSW

\begin{tabular}{|l|c|c|c|c|}
\hline Syngas (mole \%) & $\mathrm{CO}$ & $\mathrm{CO}_{2}$ & $\mathrm{H}_{2}$ & $\mathrm{CH}_{4}$ \\
\hline Experimental & 14.89 & 8.40 & 4.58 & 1.54 \\
\hline Model & 14.74 & 7.86 & 5.19 & 0.39 \\
\hline Different & -0.15 & -0.54 & -0.61 & -1.15 \\
\hline
\end{tabular}

\section{Results and discussion}

\subsection{Fuel characterization}

The initial moisture content on the wet basis of DDWS is referring to the quantity of water in the sample divided by the total mass of the sample, expressed as a percentage of the material's 
weight. During the drying process, the moisture content in DDWS was reduced, and the initial moisture content of the as-received DDWS samples was about $84.64 \%$, after $7 \mathrm{~h}$ of the drying process. By comparing the current samples with another Malaysian DDWS samples, it's found the initial moisture content of the current samples within the range 84\% [21]. The mean heating value of the DDWS was found to be $16.84 \mathrm{MJ} / \mathrm{kg}$, and it is observed this HHV is higher than the values reported in previous work [22].

Table 3. The dewatered domestic wastewater sludge fuel characterization

\begin{tabular}{|c|c|c|c|c|c|c|c|c|c|}
\hline HHV & Moisture & \multicolumn{3}{|c|}{ Proximate analysis (db\%) } & \multicolumn{5}{|c|}{ Ultimate analysis (\%) } \\
\cline { 3 - 10 }$(\mathrm{MJ} / \mathrm{kg})$ & content (\%) & VM & FC & Ash & C & H & N & S & O \\
\hline 16.84 & 84.64 & 55.42 & 18.79 & 25.79 & 34.29 & 5.20 & 5.80 & 3.12 & 25.80 \\
\hline
\end{tabular}

The DWS samples were found to contain $34.29 \%$ carbon on the average, which is in good agreement with the values reported in the literature [21]. The mean percentage of Hydrogen in DWS was found to be $5.20 \%$, and when compared to previous work, as reported in $[23,24]$, the value of hydrogen in the current work is higher. The nitrogen and sulfur content in the samples were $6 \%$ and $3.12 \%$ respectively, and these values it's found to be higher than the values reported in [22].

The TGA results for DWS show that the volatile matter (d.b.) in the samples was $55.42 \%$ (d.b.) higher than the range reported in previous work carried out by Puchong [25] who reported 53.2\% (d.b). The fixed carbon (d.b.) in the current DWS samples was found to be approximately double the value that obtained by Puchong (8.6\%) [25]. The samples in this work were also found to contain a lesser amount of ash when compared to Puchong result [25].

\subsection{Gasification simulation model}

\subsubsection{Reaction temperature}

In this study, the reaction temperature varied from 673 to 1673 K. From Fig. 5, it's observed that the rate of carbon gasification increase with the increase in the reaction temperature. Ramzan et al. [20] reported that, at low temperatures, the carbon present in biomass is not gasified completely. On another hand, the $\mathrm{CO}$ composition was increased due to endothermic reduction reaction. Hence, many studies mentioned that $\mathrm{CO}$ will have a better chance to reach equilibrium at high reaction temperature as elaborated in [26, 27]. Furthermore, $\mathrm{CH}_{4}$ presented in syngas, at low temperatures, can convert into $\mathrm{H}_{2}$ by reversing the methanation reaction. In particular, $\mathrm{H}_{2}$ production sharply increased between a temperature 673 to $973 \mathrm{~K}$, and it slightly decreased at high temperature. The decrease in $\mathrm{CO}_{2}$ production at high temperature can be related to the increase in the production of other gases $\left(\mathrm{H}_{2}\right.$ and $\left.\mathrm{CO}\right)$. From these results, it can be concluded that the increase in the gasification temperature favors $\mathrm{CO}$ and $\mathrm{H}_{2}$ production. 


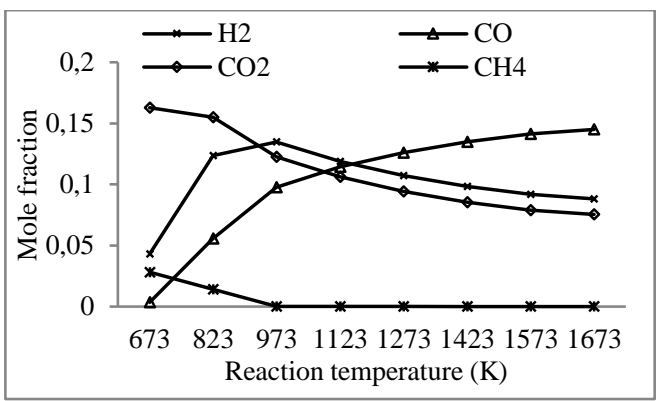

Figure 3. The effect of reaction temperature on the syngas composition from DDWS

\subsubsection{Reaction pressure}

The sensitivity analysis of the reaction pressure inside the reactor was carried out to explore its effect on the syngas composition. The reaction pressure varied from 0 to $40 \mathrm{bar}$. The mole fraction of $\mathrm{CO}$ and $\mathrm{H}_{2}$ decreased rapidly with a slight change in $\mathrm{CH}_{4}$ at high reaction pressure, as shown in Fig. 6. This result agrees with the result obtained by Higman and Van der Burgt [15].

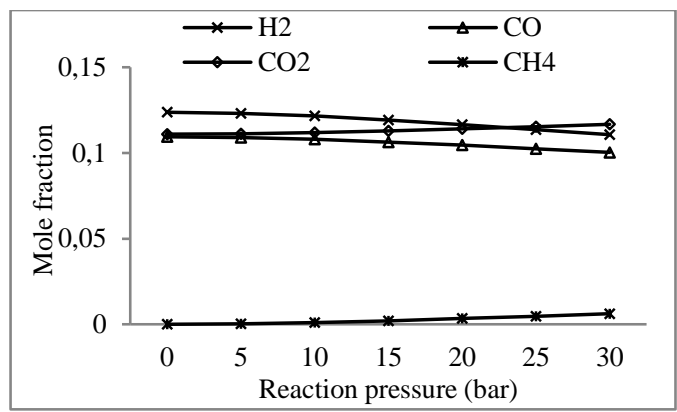

Figure 3. The effect of reaction pressure on the syngas composition from DDWS

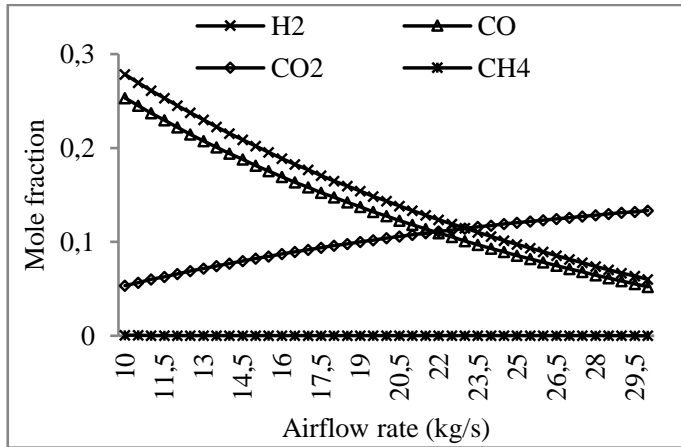

Figure 4. The effect of airflow rate on the syngas composition from DDWS

\subsubsection{Airflow rate}

In general, the oxygen is necessary to convert the elemental composition presented in the DDWS into syngas, but the excess oxygen will reduce the quality of produced syngas. In order to obtain the sufficient oxygen required for syngas production, the airflow rate $(10-30 \mathrm{~kg} / \mathrm{s})$ were investigated. From the results in Fig. 4, it can be illustrated that $\mathrm{H}_{2}$ and $\mathrm{CO}$ production decreased with increase in airflow rate, whereas $\mathrm{CO}_{2}$ production increased. This results because the excess 
air shifts the process from gasification to complete combustion [5].

\subsubsection{Moisture content}

In this study, the moisture content varied from 10 to $40 \%$ and the high heating value was calculated based on the equation obtained by Waldheim and Nilsson [28]. The increase in the DDWS initial moisture content strongly decreased the high heating value of produced syngas. It's suggested this result because a part of the DDWS heating value is used to evaporate the moisture content.

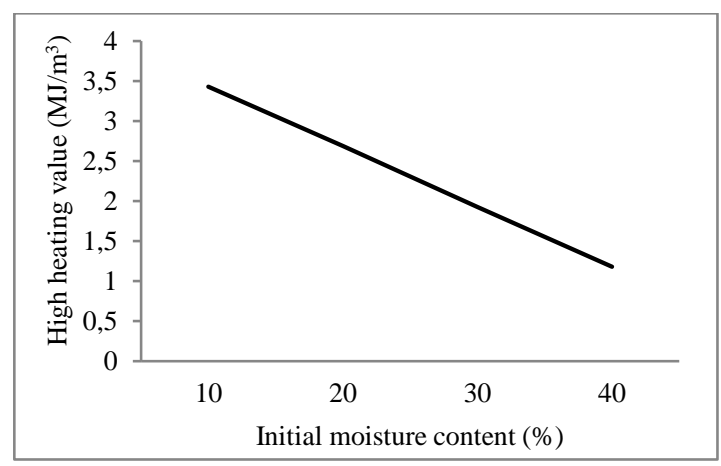

Figure 4. The effect of initial moisture content on the syngas high heating value

\section{Conclusions}

The essential fuel characterization and gasification model for the DDWS were successfully carried out. DDWS showed high potential of energy with relatively high heating value and acceptable elemental composition. This developed gasification model revealed a capable to predict the syngas composition under different operating parameters. The obtained results are in agreement with previous studies. High reaction temperature enhanced the gasification efficiency via increases in the $\mathrm{CO}$ and $\mathrm{H}_{2}$ production whereas the reaction pressure showed adversely affect. The conversion of carbon presented in DDWS through the gasification process is mainly controlled by the airflow rate. The increase of moisture content in DDWS decreases the HHV of syngas. In the future, further study in the gasification process using comprehensive models is recommended. Finally, validate these models with the experimental results.

\section{Acknowledgements}

This study was supported by the Çukurova University, Turkey under grant FBA20178013.

\section{References}

[1] Werther J, Ogada T. Sewage sludge combustion. Progress in Energy and Combustion Science 1999;25:55-116.

[2] Ibrahim ABA. Development of fuel briquettes from biomass residue. Malaysia: Universiti Teknologi PETRONAS; 2013. 
[3] Alam MZ, Muyibi SA, Wahid R. Statistical optimization of process conditions for cellulase production by liquid state bioconversion of domestic wastewater sludge. Bioresource Technology 2008;99:4709-16.

[4] Molla AH, Fakhru'l-Razi A, Abd-Aziz S, Hanafi MM, Roychoudhury PK, Alam MZ. A potential resource for bioconversion of domestic wastewater sludge. Bioresource Technology 2002;85:263-72.

[5] Ibrahim ABA, Akilli H. Supercritical water gasification of wastewater sludge for hydrogen production. International Journal of Hydrogen Energy 2019;44:10328-49.

[6] Bhoi PR, Huhnke RL, Kumar A, Indrawan N, Thapa S. Co-gasification of municipal solid waste and biomass in a commercial scale downdraft gasifier. Energy 2018;163:513-8.

[7] Diyoke C, Gao N, Aneke M, Wang M, Wu C. Modelling of down-draft gasification of biomass - An integrated pyrolysis, combustion and reduction process. Applied Thermal Engineering 2018;142:444-56.

[8] Susastriawan AAP, Saptoadi H, Purnomo. Small-scale downdraft gasifiers for biomass gasification: A review. Renewable and Sustainable Energy Reviews 2017;76:989-1003.

[9] Kumar U, Salem AM, Paul MC. Investigating the thermochemical conversion of biomass in a downdraft gasifier with a volatile break-up approach. Energy Procedia 2017;142:822-8.

[10] Han J, Liang Y, Hu J, Qin L, Street J, Lu Y, et al. Modeling downdraft biomass gasification process by restricting chemical reaction equilibrium with Aspen Plus. Energy Conversion and Management 2017;153:641-8.

[11] Kirsanovs V, Blumberga D, Veidenbergs I, Rochas C, Vigants E, Vigants G. Experimental investigation of downdraft gasifier at various conditions. Energy Procedia 2017;128:332-8.

[12] McKendry P. Energy production from biomass (part 3): gasification technologies. Bioresource Technology 2002;83:55-63.

[13] Liu H, Hu J, Wang H, Wang C, Li J. Experimental studies of biomass gasification with air. Journal of Natural Gas Chemistry 2012;21:374-80.

[14] Wang Z, He T, Qin J, Wu J, Li J, Zi Z, et al. Gasification of biomass with oxygen-enriched air in a pilot scale two-stage gasifier. Fuel 2015;150:386-93.

[15] Higman C, Van der Burgt M. Gasification 2nd Edn.: Gulf Professional Publishing, Burlington; 2008.

[16] Kaupp A, Goss J. State-of-the-art report for small scale (to $50 \mathrm{kw}$ ) gas producer-engine systems. California Univ., Davis (USA). Dept. of Agricultural Engineering; 1981. 
[17] Olgun H, Ozdogan S, Yinesor G. Results with a bench scale downdraft biomass gasifier for agricultural and forestry residues. Biomass and Bioenergy 2011;35:572-80.

[18] Prabhakar A, Sadhukhan AK, Bhunia S, Gupta P. Modelling and experimental investigations on gasification of coarse sized coal char particle with steam. Journal of the Energy Institute 2018.

[19] Gambarotta A, Morini M, Zubani A. A non-stoichiometric equilibrium model for the simulation of the biomass gasification process. Applied Energy 2018;227:119-27.

[20] Ramzan N, Ashraf A, Naveed S, Malik A. Simulation of hybrid biomass gasification using Aspen plus: A comparative performance analysis for food, municipal solid and poultry waste. Biomass and Bioenergy 2011;35:3962-9.

[21] Abbas A, Ibrahim A, Nor M, Aris M. Characterization of Malaysian domestic sewage sludge for conversion into fuels for energy recovery plants. 2011 National Postgraduate Conference: IEEE; 2011. p. 1-4.

[22] Jiang J, Du X, Yang S. Analysis of the combustion of sewage sludge-derived fuel by a thermogravimetric method in China. Waste Management 2010;30:1407-13.

[23] P. Thipkhunthoda VM, P. Rangsunvigita, B. Kitiyanana, T. Rirksomboon. Predicting the heating value of sewage sludge in Thailand from proximate and ultimate analyses. Fuel 2005;84:849-57.

[24] T. Gerhardt RC, V. Siegle, H. Spliethoff, K. R. G. Hein, “,”, Spring Dallas 43 (1). . Fuel characteristics of sewage sludge and other supplemental fuels regarding their effect on the cocombustion process with coal. Combustion Chemistry of Traditional and Non-Traditional Fuels. Dallas.

[25] Thipkhunthod P, Meeyoo V, Rangsunvigit P, Kitiyanan B, Siemanond K, Rirksomboon T. Predicting the heating value of sewage sludges in Thailand from proximate and ultimate analyses. Fuel 2005;84:849-57.

[26] Shen L, Gao Y, Xiao J. Simulation of hydrogen production from biomass gasification in interconnected fluidized beds. Biomass and Bioenergy 2008;32:120-7.

[27] Detournay M, Hemati M, Andreux R. Biomass steam gasification in fluidized bed of inert or catalytic particles: Comparison between experimental results and thermodynamic equilibrium predictions. Powder Technology 2011;208:558-67.

[28] Waldheim L, Nilsson T. HEATING VALUE OF GASES FROM BIOMASS GASIFICATION In: TPS-01/16, editor. IEA Bioenergy Agreement subcommittee on Thermal Gasification of Biomass. TPS Termiska Processer AB, Studsvik, e-post tps@tps.se 2001. 